\title{
APPLICATION OF REPEATED AVERAGE METHOD ON GENERALIZED FUZZY SOFT MATRIX FOR DECISION MAKING
}

\author{
M. K. HASAN ${ }^{1 *}$, M. M. RAHMAN ${ }^{2}$ AND ABEDA SULTANA ${ }^{3}$ \\ ${ }^{l}$ Department of Mathematics and Statistics, Bangladesh University of Business and \\ Technology (BUBT), Dhaka Bangladesh \\ ${ }^{2}$ Department of Mathematics, Jagannath University, Dhaka, Bangladesh \\ ${ }^{3}$ Department of Mathematics, Jahangirnagar University, Dhaka, Bangladesh
}

\begin{abstract}
Molodtsov introduced the theory of soft sets, which can be seen as a new mathematical approach to vagueness. Maji and his associates have further initiated several basic notions of soft set theory. They have also introduced the concept of fuzzy soft set, a more generalized concept, which is a combination of fuzzy set and soft set. In this paper, Repeated Average Method has been used in Generalized Fuzzy Soft Matrix for prompt decision making.
\end{abstract}

Key words: Fuzzy soft matrix, Expert generalized fuzzy soft matrix, Repeated average

\section{Introduction}

The concept of soft sets was first formulated by Molodtsov (1999) as a completely new mathematical tool for solving problems dealing with uncertainties. Soft set is a parameterized general mathematical tool which deal with a collection of approximate descriptions of objects. Maji et al. (2003) presented a detailed theoretical study of soft sets which included subset and super set of a soft set, equality of soft sets, operations on soft sets such as union, intersection, AND and OR- operations among others. They also studied and discussed the basic properties of these operations. Furthermore, Maji et al. (2003) worked on soft set theory. Maji et al. (2001) also presented the definition of fuzzy soft set and Mondal et al. (2013) presented some applications of this notion to decision making problems. Babitha and Sunil (2010) introduced the concept of soft set relation and function and discussed many related concepts such as equivalence soft set relation, partition of soft sets, ordering on soft sets. In continuation of their work, Babitha and Sunil (2011) further worked on soft set relation and ordering by introducing the concept of anti-symmetric relation and transitive closure of a soft set relation. Singh (2012) and Onyeozili (2012) proved that the operations defined on soft sets are equivalent to the corresponding operations defined on their soft matrices. Cagman et al. (2010) defined soft matrix which is representation of soft set, to make operations in theoretical studies in soft set more functional. This representation has several advantages. Borah et al. (2012) extended fuzzy

*Author for correspondence: <krul.habi@yahoo.com>. 
soft matrix decision making method by using fuzzy soft T-product. Basu et al. (2012) have introduced some operations on fuzzy soft matrices and choice matrices. Majumdar (2010) and Samanta (2010) has introduced the notion of generalized fuzzy soft sets and have applied this set in decision making. Repeated average method (Hasan et al. 2019) has been applied in generalized fuzzy soft matrix for instant decision making. Also a problem has been solved to illustrate and compared the results with other result solved by other existing method.

\section{Preliminaries}

In this section, authors present the notion of soft sets introduced by Molodtsov (1999), and some useful definitions from the literature.

Soft set (Molodtsov 1999)

Suppose $U$ be a universal set and $\mathrm{E}$ be a set of parameters or attributes w.r. to $U$. Let $\mathrm{P}(\mathrm{U})$ denote the power set of $\mathrm{U}$ and $A \subseteq \mathrm{E}$. A pair $(F, A)$ is called a soft set over $U$, where $F$ is a mapping given by $F: E \rightarrow P(U)$. Thus $(F, A)$ is defined as

$$
(F, A)=\{F(e) \in P(U): e \in E, F(e)=\phi \text { if } e \notin A\}
$$

For $e \in A, F(e)$ may be considered as the set of e-element or e-approximate elements of the soft $\operatorname{set}(F, A)$.

Fuzzy soft set (Maji et al. 2003)

Suppose $U$ be an initial universal set and $\mathrm{E}$ be a set of parameters and $A \subseteq \mathrm{E}$.A pair $\left(F_{A}, E\right)$ is called a fuzzy soft set (FSS) over $U$, where $F_{A}$ is a mapping given by $F_{A}: E \rightarrow I^{U}$, where $I^{U}$ denotes the collection of all fuzzy subsets of $U$.

Fuzzy soft matrices (Cagman and Enginoglu 2012)

Let $U=\left\{u_{1}, u_{2}, u_{3}, \ldots \ldots \ldots \ldots \ldots, u_{m}\right\}$ be the universal set and $E=\left\{e_{1}, e_{2}, e_{3}, \ldots \ldots \ldots \ldots \ldots ., e_{n}\right\}$ be the set of parameters. Let $A \subseteq E$ and $(F, A)$ be a fuzzy soft set in the fuzzy soft class $(U, E)$. Then we would represent the fuzzy soft set $(F, A)$, in matrix form as $A_{m \times n}=\left[a_{i j}\right]_{m \times n}$ or simply by $A=\left[a_{i j}\right]$, where $a_{i j}=\left\{\begin{array}{cc}\mu_{j}\left(u_{i}\right) & ; e_{j} \in A \\ 0 & ; e_{j} \notin A\end{array}\right.$ and $\quad i=1,2,3 \ldots \ldots \ldots \ldots . m \quad ; j=1,2,3 \ldots \ldots \ldots \ldots \ldots .$.

Here $\mu_{j}\left(u_{i}\right)$ represents the membership of $u_{i}$ in the fuzzy set $F\left(e_{j}\right)$. We would identify a fuzzy soft set with its fuzzy soft matrix and use these two concepts interchangeable. The set of all $m \times n$ fuzzy soft matrixes would be denoted by $F S M_{m \times n}$. 


\section{Example}

Let $U=\left\{u_{1}, u_{2}, u_{3}, u_{4}\right\}$ be the universal set and $E=\left\{e_{1}, e_{2}, e_{3}, e_{4}, e_{5}\right\}$ be the set of parameters. Let $P=\left\{e_{1}, e_{2}, e_{4}\right\} \subseteq E$ and $(F, P)$ be a fuzzy soft, where

$$
\begin{aligned}
&(F, P)=\{ F\left(e_{1}\right)=\left\{\left(u_{1}, 0.7\right),\left(u_{2}, 0.6\right),\left(u_{3}, 0.7\right),\left(u_{4}, 0.5\right)\right\} \\
& F\left(e_{2}\right)=\left\{\left(u_{1}, 0.8\right),\left(u_{2}, 0.6\right),\left(u_{3}, 0.1\right),\left(u_{4}, 0.5\right)\right\} \\
&\left.F\left(e_{4}\right)=\left\{\left(u_{1}, 0.1\right),\left(u_{2}, 0.4\right),\left(u_{3}, 0.7\right),\left(u_{4}, 0.3\right)\right\}\right\}
\end{aligned}
$$

The fuzzy soft matrix representing this fuzzy soft set would be represented in our notation as

$$
A=\left[\begin{array}{lllll}
0.7 & 0.8 & 0.0 & 0.1 & 0.0 \\
0.6 & 0.6 & 0.0 & 0.4 & 0.0 \\
0.7 & 0.1 & 0.0 & 0.7 & 0.0 \\
0.5 & 0.5 & 0.0 & 0.3 & 0.0
\end{array}\right]
$$

Fuzzy soft column matrix (Cagman and Enginoglu 2010)

Let $A=\left[a_{i j}\right] \in F S M_{m \times n}$, where $a_{i j}=\mu_{j}\left(u_{i}\right)$. If $n=1$, then A is called a fuzzy soft column matrix.

Arithmetic mean (AM) of a fuzzy soft matrix (Mondal and Roy 2013)

Let $A=\left[a_{i j}\right] \in F S M_{m \times n}$. Then the arithmetic mean of fuzzy soft matrix of membership value

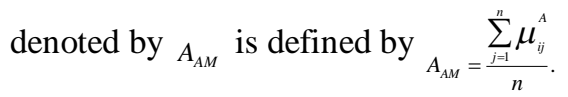

\section{Example}

Let $A=\left[\begin{array}{lll}0.50 & 0.22 & 0.35 \\ 0.65 & 0.81 & 0.70 \\ 0.55 & 1.00 & 0.40\end{array}\right]$. Then $A_{A M}=\left[\begin{array}{c}0.357 \\ 0.72 \\ 0.65\end{array}\right]$

Generalized fuzzy soft set (Majumder and Samanta 2010)

Let $U=\left\{u_{1}, u_{2}, u_{3}, \ldots \ldots \ldots, u_{m}\right\}$ be the universal set of elements and $E=\left\{e_{1}, e_{2}, e_{3}, \ldots \ldots \ldots ., e_{n}\right\}$ be the set of parameters. The pair $(U, E)$ will be called soft universe. Let $F: E \rightarrow I^{U}$ and $\lambda$ be a fuzzy subset of $E$ i.e. $\lambda: E \rightarrow I=[0,1], I^{U}$ is the collection of all fuzzy subsets of $U$.

Let $F_{\lambda}: E \rightarrow I^{U} \times I$ be a function define as $F_{\lambda}(e)=(F(e), \lambda(e))$, where $F(e) \in I^{U}$. Then $F_{\lambda}$ is called the generalized fuzzy soft set over the soft universe $(U, E)$. Here for each parameters $e_{i}, F_{\lambda}\left(e_{i}\right)=\left(F\left(e_{i}\right), \lambda\left(e_{i}\right)\right)$ indicates not only the degree of belongingness of the 
elements of $U$ in $F\left(e_{i}\right)$ but also the degree of possibility of such belongingness which is represented by $\lambda\left(e_{i}\right)$.

\section{Example}

Let $U=\left\{s_{1}, s_{2}, s_{3}, s_{4}\right\}$ be the set of students under consideration and $E=\left\{e_{1}, e_{2}, e_{3}, e_{4}, e_{5}\right\}$ be the set of parameters, where $e_{1}=$ expert in Mathematics, $e_{2}=$ expert in Chemistry, $e_{3}=$ expert in Physics, $e_{4}=$ expert in Biology and $e_{5}=$ expert in English. Let $A=\left\{e_{2}, e_{3}, e_{4}\right\} \subseteq E$. Let $\lambda: E \rightarrow I=[0,1]$ be given as:

$\lambda\left(e_{2}\right)=0.6, \lambda\left(e_{3}\right)=0.5$ and $\lambda\left(e_{4}\right)=0.7$.

We define $F_{\lambda}$ as follows:

$F_{\lambda}\left(e_{2}\right)=\left(\left\{s_{1} / 0.5, s_{2} / 0.7, s_{3} / 0.4, s_{4} / 0.2\right\}, 0.6\right)$

$F_{\lambda}\left(e_{3}\right)=\left(\left\{s_{1} / 0.2, s_{2} / 0.3, s_{3} / 0.5, s_{4} / 0.1\right\}, 0.5\right)$

$F_{\lambda}\left(e_{4}\right)=\left(\left\{s_{1} / 0.3, s_{2} / 0.1, s_{3} / 0.2, s_{4} / 0.4\right\}, 0.7\right)$

which is the generalized fuzzy soft set representing overall expert of the students.

In tabular form it can be expressed as

\begin{tabular}{|c|c|c|c|c|c|}
\hline \multirow{6}{*}{$F_{\lambda}$} & & & $e_{2}$ & $e_{3}$ & $e_{4}$ \\
\hline & & $s_{1}$ & 0.5 & 0.2 & 0.3 \\
\hline & & $s_{2}$ & 0.7 & 0.3 & 0.1 \\
\hline & & $s_{3}$ & 0.4 & 0.5 & 0.2 \\
\hline & & $S_{4}$ & 0.2 & 0.1 & 0.4 \\
\hline & & & 0.6 & 0.5 & 0.7 \\
\hline
\end{tabular}

In matrix form it can be expressed as

\begin{tabular}{|c|c|c|c|c|c|}
\hline \multirow{5}{*}{$F_{\lambda}=$} & $e_{1}$ & $e_{2}$ & $e_{3}$ & $e_{4}$ & $e_{5}$ \\
\hline & $s_{1}[(0.0,0.0)$ & $(0.5,0.6)$ & $(0.2,0.5)$ & $(0.3,0.7)$ & $(0.0,0.0)$ \\
\hline & \begin{tabular}{l|l}
$s_{2}$ & $(0.0,0.0)$
\end{tabular} & $(0.7,0.6)$ & $(0.3,0.5)$ & $(0.1,0.7)$ & $(0.0,0.0)$ \\
\hline & \begin{tabular}{l|l}
$s_{3}$ & $(0.0,0.0)$
\end{tabular} & $(0.4,0.6)$ & $(0.5,0.5)$ & $(0.2,0.7)$ & $(0.0,0.0)$ \\
\hline & $s_{4}[(0.0,0.0)$ & $(0.2,0.6)$ & $(0.1,0.5)$ & $(0.4,0.7)$ & $(0.0,0.0)$ \\
\hline
\end{tabular}

Generalized fuzzy soft matrix (Saikia et al. 2014)

Let $U$ be an initial universe, $E$ be a set of parameters and $A \subseteq E$. Let $\left(F_{\lambda}, E\right)$ be a generalized fuzzy soft set over $(U, E)$. Then a subset of $U \times E$ is uniquely defined by $R_{A}=\left\{(u, e): e \in A, u \in F_{\lambda}(e)\right\}$ which called a relation form of $\left(F_{\lambda}, E\right)$. The membership function $\mu_{R_{A}}$ and the function $\lambda_{R_{A}}$ are written by $\mu_{R_{A}}: U \times E \rightarrow[0,1]$ and $\lambda_{R_{A}}: U \times E \rightarrow[0,1]$, where $\mu_{R_{A}}:(u, e) \in[0,1]$ is the membership value of $u \in U$ for each $e \in E$ and $\lambda_{R_{A}}:(u, e) \in[0,1]$. 
If $\left[\mu_{i j}, \lambda_{j}\right]_{m \times n}=\left(\mu_{R_{A}}\left(u_{i}, e_{j}\right), \lambda_{j}\left(u_{i}, e_{j}\right)\right)$, we define a matrix

$$
\left[\mu_{i j}, \lambda_{j}\right]_{m \times n}=\left[\begin{array}{cccc}
\left(\mu_{11}, \lambda_{1}\right) & \left(\mu_{12}, \lambda_{2}\right) & \ldots \ldots . & \left(\mu_{1 n}, \lambda_{n}\right) \\
\left(\mu_{21}, \lambda_{1}\right) & \left(\mu_{22}, \lambda_{2}\right) & \ldots \ldots . & \left(\mu_{2 n}, \lambda_{n}\right) \\
: & : & : & : \\
\left(\mu_{m 1}, \lambda_{1}\right) & \left(\mu_{m 2}, \lambda_{2}\right) & \ldots \ldots & \left(\mu_{m n}, \lambda_{n}\right)
\end{array}\right]
$$

which is called an $m \times n$ generalized fuzzy soft matrix (GFSM) of generalized fuzzy soft $\operatorname{set}(\mathrm{GFSS})\left(F_{\lambda}, E\right)$.

Therefore, we can say that a generalized fuzzy soft set $\left(F_{\lambda}, E\right)$ is uniquely characterized by the matrix $\left[\mu_{i j}, \lambda_{j}\right]_{m \times n}$ and both concepts are interchangeable. The set of all $m \times n$ fuzzy soft matrices over $U$ will be denoted by $G F S M_{m \times n}$.

\section{Example}

Let $U=\left\{u_{1}, u_{2}, u_{3}\right\}$ be the set of the students under consideration for the best academic year with respect the given parameters $E=\left\{e_{1}, e_{2}, e_{3}, e_{4}\right\}$, where $e_{1}=$ result, $e_{2}=$ conduct, $e_{3}=$ attendance, $e_{4}=$ games and sports.

Consider $A=\left\{e_{1}, e_{2}, e_{4}\right\} \subseteq E$. Let $\lambda: E \rightarrow I=[0,1]$ be given as:

$\lambda\left(e_{1}\right)=0.8, \lambda\left(e_{2}\right)=0.7$ and $\lambda\left(e_{4}\right)=0.6$.

We define $F_{\lambda}$ as follows:

$F_{\lambda}\left(e_{1}\right)=\left(\left\{u_{1} / 0.4, u_{2} / 0.5, u_{3} / 0.6\right\}, 0.8\right)$

$F_{\lambda}\left(e_{2}\right)=\left(\left\{u_{1} / 0.5, u_{2} / 0.7, u_{3} / 0.2\right\}, 0.7\right)$

$F_{\lambda}\left(e_{4}\right)=\left(\left\{u_{1} / 0.2, u_{2} / 0.3, u_{3} / 0.5\right\}, 0.6\right)$

We can write the above set as follows:

\begin{tabular}{l|cccc}
$R_{A}$ & $e_{1}$ & $e_{2}$ & $e_{3}$ & $e_{4}$ \\
$u_{1}$ & $\left(u_{11}, \lambda_{1}\right)$ & $\left(u_{12}, \lambda_{2}\right)$ & $\left(u_{13}, \lambda_{3}\right)$ & $\left(u_{14}, \lambda_{4}\right)$ \\
$u_{2}$ & $\left(u_{21}, \lambda_{1}\right)$ & $\left(u_{22}, \lambda_{2}\right)$ & $\left(u_{23}, \lambda_{3}\right)$ & $\left(u_{24}, \lambda_{4}\right)$ \\
$u_{3}$ & $\left(u_{31}, \lambda_{1}\right)$ & $\left(u_{32}, \lambda_{2}\right)$ & $\left(u_{33}, \lambda_{3}\right)$ & $\left(u_{34}, \lambda_{4}\right)$
\end{tabular}


Then the generalized fuzzy soft matrix can be written as follows:

$\left[\mu_{i j}, \lambda_{j}\right]_{3 \times 4}=\left[\begin{array}{llll}(0.4,0.8) & (0.5,0.7) & (0,0) & (0.2,0.6) \\ (0.5,0.8) & (0.7,0.7) & (0,0) & (0.3,0.6) \\ (0.6,0.8) & (0.2,0.7) & (0,0) & (0.5,0.6)\end{array}\right]$

Intersection of two generalized fuzzy soft matrices (Saikia et al. 2014)

Let $\left[a_{i j}, \lambda_{j}\right],\left[b_{i j}, \lambda_{j}^{\prime}\right] \in \operatorname{GFSM}_{m \times n}$. Then the GFSM $\left[c_{i j}, \gamma_{j}\right]$ is called intersection of $\left[a_{i j}, \lambda_{j}\right]$ and $\left[b_{i j}, \lambda_{j}^{\prime}\right]$, denoted by $\left[a_{i j}, \lambda_{j}\right] \cap\left[b_{i j}, \lambda_{j}^{\prime}\right]$, if $c_{i j}=\min \left\{a_{i j}, b_{i j}\right\}$ and $\gamma_{j}=\max \left\{\lambda_{j}, \lambda_{j}^{\prime}\right\}$ for all $i, j$.

\section{Example}

$\operatorname{Let}\left[a_{i j}, \lambda_{j}\right],\left[b_{i k}, \gamma_{k}\right] \in G F S M_{m \times n}$, where $\left[a_{i j}, \lambda_{j}\right]=\left[\begin{array}{lll}(0.4,0.5) & (0.5,0.7) & (0.2,0.6) \\ (0.5,0.5) & (0.7,0.7) & (0.3,0.6) \\ (0.6,0.5) & (0.2,0.7) & (0.4,0.6)\end{array}\right]$ and $\left[b_{i k}, \gamma_{k}\right]=\left[\begin{array}{rrr}(0.7,0.3) & (0.2,0.5) & (0.3,0.4) \\ (0.4,0.3) & (0.3,0.5) & (0.2,0.4) \\ (0.5,0.3) & (0.6,0.5) & (0.5,0.4)\end{array}\right]$

Then

$$
\begin{aligned}
& {\left[a_{i j}, \lambda_{j}\right] \wedge\left[b_{i k}, \gamma_{k}\right] } \\
= & {\left[\begin{array}{llllllllll}
(0.4,0.5) & (0.2,0.5) & (0.3,0.5) & (0.5,0.7) & (0.2,0.7) & (0.3,0.7) & (0.2,0.6) & (0.2,0.6) & (0.2,0.6) \\
(0.4,0.5) & (0.3,0.5) & (0.2,0.5) & (0.4,0.7) & (0.3,0.7) & (0.2,0.7) & (0.3,0.6) & (0.3,0.6) & (0.2,0.6) \\
(0.5,0.5) & (0.6,0.5) & (0.5,0.5) & (0.2,0.7) & (0.2,0.7) & (0.2,0.7) & (0.4,0.6) & (0.4,0.6) & (0.4,0.6)
\end{array}\right] }
\end{aligned}
$$

\section{Definitions}

\section{Expert generalized fuzzy soft matrix}

$\operatorname{Let}\left[a_{i j}^{1}, \mu_{j}^{1}\right],\left[a_{i j}^{2}, \mu^{2}{ }_{j}\right], \ldots \ldots \ldots,\left[a_{i j}^{n}, \mu^{n}{ }_{j}\right] \in G^{\prime} S_{m \times n}$ such that

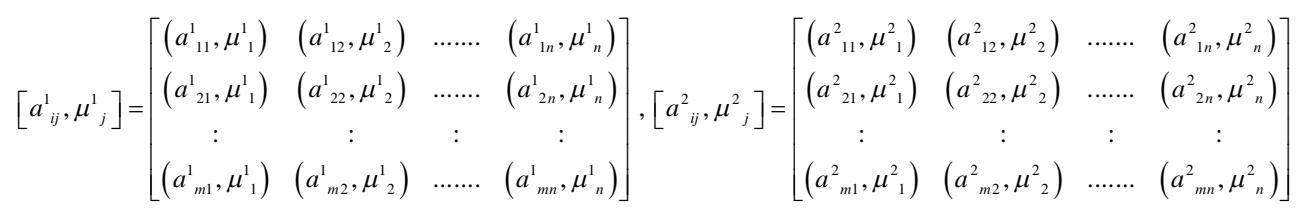

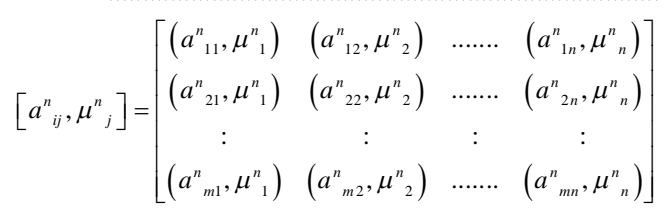

These are considered as expert generalized fuzzy soft matrices. 


\section{Mean score expert generalized fuzzy soft matrices}

Consider the above expert generalized fuzzy soft matrices. Then the mean score generalized fuzzy soft matrix is defined as follows:

$$
\begin{aligned}
& {\left[\begin{array}{cccc}
\left(\frac{a_{11}^{1}+a_{11}^{2}+\ldots .+a_{11}^{n}}{n}, \frac{\mu_{1}^{1}+\mu_{1}^{2}+\ldots .+\mu_{1}^{n}}{n}\right) & \left(\frac{a_{12}^{1}+a_{12}^{2}+\ldots .+a_{12}^{n}}{n}, \frac{\mu_{2}^{1}+\mu_{2}^{2}+\ldots .+\mu_{2}^{n}}{n}\right) & \ldots . . . & \left(\frac{a_{1 n}^{1}+a_{1 n}^{2}+\ldots .+a_{1 n}^{n}}{n}, \frac{\mu_{n}^{1}+\mu_{n}^{2}+\ldots .+\mu_{n}^{n}}{n}\right) \\
\left(\frac{a_{21}^{1}+a_{21}^{2}+\ldots .+a_{21}^{n}}{n}, \frac{\mu_{1}+\mu_{1}^{2}+\ldots .+\mu_{1}^{n}}{n}\right) & \left(\frac{a_{22}^{1}+a_{22}^{2}+\ldots .+a_{2 n}^{n}}{n}, \frac{\mu_{2}+\mu_{2}^{2}+\ldots .+\mu_{2}^{n}}{n}\right) & \ldots \ldots & \left(\frac{a_{2 n}^{1}+a_{2 n}^{2}+\ldots .+a_{2 n}^{n}}{n}, \frac{\mu_{n}^{1}+\mu_{n}^{2}+\ldots .+\mu_{n}^{n}}{n}\right) \\
: & : & : \\
\left(\frac{a_{m 1}^{1}+a_{m 1}^{2}+\ldots .+d_{m 1}^{n}}{n}, \frac{\mu_{1}^{1}+\mu_{1}^{2}+\ldots .+\mu_{1}^{n}}{n}\right)\left(\frac{a_{m 2}^{1}+a_{m 2}^{2}+\ldots .+d_{m 2}^{n}}{n}, \frac{\mu_{2}^{1}+\mu_{2}^{2}+\ldots .+\mu_{2}^{n}}{n}\right) & \ldots \ldots . & \left(\frac{a_{m}^{1}+a_{m n}^{2}+\ldots .+d_{m}^{n}}{n}, \frac{\mu_{n}^{1}+\mu_{n}^{2}+\ldots .+\mu_{n}^{n}}{n}\right)
\end{array}\right]} \\
& {\left[\begin{array}{cccc}
\left(a_{11}, \mu_{1}\right) & \left(a_{12}, \mu_{2}\right) & \ldots \ldots . . & \left(a_{1 n}, \mu_{n}\right) \\
\left(a_{21}, \mu_{1}\right) & \left(a_{22}, \mu_{2}\right) & \ldots \ldots . . & \left(a_{2 n}, \mu_{n}\right) \\
\vdots & \vdots & : & : \\
\left(a_{m 1}, \mu_{1}\right) & \left(a_{m 2}, \mu_{2}\right) & \ldots \ldots . . & \left(a_{m 1}, \mu_{n}\right)
\end{array}\right] \text { (say) }}
\end{aligned}
$$

\section{Decision generalized fuzzy soft matrix}

Consider the above expert generalized fuzzy soft matrices. Then the weighted mean of generalized fuzzy soft matrix is defined as follows:

$$
\left[\begin{array}{c}
\frac{a_{11} \times \mu_{1}+a_{12} \times \mu_{2}+\ldots \ldots \ldots .+a_{1 n} \times \mu_{n}}{\mu_{1}+\mu_{2}+\ldots \ldots \ldots .+\mu_{n}} \\
\frac{a_{21} \times \mu_{1}+a_{22} \times \mu_{2}+\ldots \ldots \ldots .+a_{2 n} \times \mu_{n}}{\mu_{1}+\mu_{2}+\ldots \ldots \ldots . \mu_{n}} \\
: \\
: \\
\vdots \\
\frac{a_{m 1} \times \mu_{1}+a_{m 2} \times \mu_{2}+\ldots \ldots \ldots .+a_{m n} \times \mu_{n}}{\mu_{1}+\mu_{2}+\ldots \ldots \ldots . .+\mu_{n}}
\end{array}\right]
$$

\section{Generalized fuzzy soft standard deviation}

Standard deviation may be defined as the positive square root of the arithmetic mean of the squares of deviations of given observations from their arithmetic mean. For ungrouped data, the standard deviation is

$$
\sigma=\sqrt{\frac{\sum X^{2}}{N}-\left(\frac{\sum X}{N}\right)^{2}}
$$

Here $X$ are the entries $(0 \leq X \leq 1)$ from the Mean Score Generalized Fuzzy Soft Matrices and maximum score in Decision Fuzzy Soft Matrix will be considered as mean. 


\section{Generalized fuzzy soft coefficient of variation}

The relative measure of dispersion based upon fuzzy soft standard deviation is called fuzzy soft coefficient of standard deviation. The fuzzy soft coefficient of standard deviation multiplied by 100 gives the fuzzy soft coefficient of variation.

Thus

Generalized Fuzzy Soft Coefficient of variation (C.V) $=\frac{\sigma}{\text { Mean }} \times 100$

Where, $\sigma$ and mean are both measured in the same units.

\section{Application of repeated average method in decision making}

In practical life, we face so many uncertainties in modeling real-life problems. Some of the existing mathematical methods for finding out the solution of problems related with uncertainties have been discussed earlier. Now-a-days, the world of uncertainty with its associated problems can well be handled by Soft set theory, which is a new emerging mathematical tool. Here we focus on developing an easy and trustable algorithm which is a new problem solving strategy with the association of fuzzy mathematics and statistics. This method reflects a step by step systematic algorithm to find out the optimal solution mentioned as below. In case of ties, i.e. same values in decision matrix, the coefficient of variation would provide the way out.

\section{Algorithm:}

Input: Generalized Fuzzy Soft set of $\mathrm{m}$ objects (products/students/patients/job applicants/countries etc.), each of which has n parameters (attributes).

Output: An optimum result.

Step-1: Consider the generalized fuzzy soft matrix for each expert (called Generalized Expert Fuzzy Soft Matrix).

Step-2: Compute the mean of each Generalized Expert Fuzzy Soft Matrix (called Mean Score Generalized Fuzzy Soft Matrix).

Step-3: Compute the mean of all scores from the Mean Score Generalized Fuzzy Soft Matrix (called Decision Generalized Fuzzy Soft Matrix)

Step-4: Pick up the maximum score and select the most efficient and trustable object (candidate or product).

Step-5: If ties arises fuzzy coefficient of variation (GFCV) might be applied for selecting the best object (Use the data from the Mean Score Generalized Fuzzy Soft Matrix).

\section{Case study:}

Generally in medical science a patient suffering from a disease may have multiple symptoms. Again it is also observed that there are certain symptoms which may be 
common to more than one diseases leading to diagnostic dilemma. Sometimes the doctor has to face many problems when an area is largely affected new disease. Then the doctor has detected the disease commencing the common symptoms of the patients.

In [17],$U=\left\{p_{1}, p_{2}, p_{3}, p_{4}\right\}$ be the set of patients and $E=\left\{e_{1}, e_{2}, e_{3}, e_{4}, e_{5}, e_{6}, e_{7}, e_{8}\right\}$ be the set of parameters of symptoms of dengue, where $e_{1}=$ high fever $\left(104 \mathrm{~F}, 40^{\circ} \mathrm{C}\right), e_{2}=$ headache, $e_{3}=$ extreme fatigue $e_{4}=$ red eyes and pain in the eyes, $e_{5}=$ enlarged lymph nodes, $e_{6}=$ deep muscle and joint pains (during first hours of illness), $e_{7}=$ nausea and vomiting, $e_{8}=$ low pressure and heart rate.

Suppose two Dr. X and Dr. Y examines the patients on based on the same set of parameters.

Let $\lambda: E \rightarrow[0,1]$. They consider the function on the parameters as follows: Dr. X grade on the parameters as

$\lambda\left(e_{1}\right)=0.8, \lambda\left(e_{2}\right)=0.6, \lambda\left(e_{3}\right)=0.3, \lambda\left(e_{4}\right)=0.5, \lambda\left(e_{5}\right)=0.4, \lambda\left(e_{6}\right)=0.5, \lambda\left(e_{7}\right)=0.7, \lambda\left(e_{8}\right)=0.2$ and the Dr. Y grade on the parameters as $\lambda\left(e_{1}\right)=0.7, \lambda\left(e_{2}\right)=0.5, \lambda\left(e_{3}\right)=0.4, \lambda\left(e_{4}\right)=0.3, \lambda\left(e_{5}\right)=0.6, \lambda\left(e_{6}\right)=0.4, \lambda\left(e_{7}\right)=0.7, \lambda\left(e_{8}\right)=0.3$

Based on these functions the two doctors construct generalized matrices for the patients $A$ and $B$ respectively given as follows

\begin{tabular}{|c|c|c|c|c|c|c|c|c|}
\hline$p_{1}$ & {$[(0.7,0.8)$} & $(0.6,0.6)$ & $(0.8,0.3)$ & $(0.6,0.5)$ & $(0.7,0.4)$ & $(0.5,0.5)$ & $(0.7,0.7)$ & $(0.4,0.2)$ \\
\hline & $(0.6,0.8)$ & $(0.5,0.6)$ & $(0.3,0.3)$ & $(0.1,0.5)$ & $(0.1,0.4)$ & $(0.6,0.5)$ & $(0.2,0.7)$ & $(0.5,0.2)$ \\
\hline & $(0.5,0.8)$ & $(0.4,0.6)$ & $(0.2,0.3)$ & $(0.2,0.5)$ & $(0.2,0.4)$ & $(0.3,0.5)$ & $(0.4,0.7)$ & $(0.3,0.2)$ \\
\hline$p_{4}$ & $(0.3,0.8)$ & $(0.7,0.6)$ & $(0.5,0.3)$ & $(0.3,0.5)$ & $(0.4,0.4)$ & $(0.2,0.5)$ & $(0.3,0.7)$ & $(0.5,0.2)$ \\
\hline$p_{1}$ & {$[(0.7,0.7)$} & $(0.6,0.5)$ & $(0.8,0.4)$ & $(0.6,0.3)$ & $(0.7,0.6)$ & $(0.6$, & $(0.8,0.7)$ & $(0.5$, \\
\hline & $(0.5,0.7)$ & $(0.2,0.5)$ & $(0.4,0.4)$ & $(0.4,0.3)$ & $(0.2,0.6)$ & $(0.5,0.4)$ & $(0.3,0.7)$ & $(0.4,0.3)$ \\
\hline & $(0.4,0.7)$ & $(0.3,0.5)$ & $(0.5,0.4)$ & $(0.1,0.3)$ & $(0.3,0.6)$ & $(0.2,0.4)$ & $(0.2,0.7)$ & $(0.2,0.3)$ \\
\hline$p_{4}$ & $(0.2,0.7)$ & $(0.4,0.5)$ & $(0.3,0.4)$ & $(0.2,0.3)$ & $(0.2,0.6)$ & $(0.1,0.4)$ & $(0.4,0.7)$ & $(0.3,0.3)$ \\
\hline
\end{tabular}

\section{Solution:}

Step-1: The Expert Generalized Fuzzy Soft Matrices are

\begin{tabular}{|c|c|c|c|c|c|c|c|c|}
\hline$p_{1}$ & & & & & & & & \\
\hline & & & & & & ) & & \\
\hline & & & & & & & & \\
\hline . & & & & & & & & \\
\hline & & & & & & & & \\
\hline & 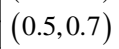 & 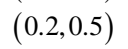 & $(0.4$ & & & & & \\
\hline & 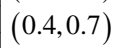 & 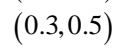 & $(0.5$ & $(0$. & $(0$ & ) & 7) & $(0.2,0$ \\
\hline & $0.2,0.7)$ & $(0.4,0.5)$ & $(0.3,0.4)$ & $(0.2,0.3)$ & $(0.2,0.6)$ & $(0.1,0.4)$ & $(0.4,0.7)$ & $(0.3,0$ \\
\hline
\end{tabular}


Step-2: The Mean score generalized fuzzy soft matrices are

$$
M[A, B]=\begin{aligned}
& p_{1} \\
& p_{2} \\
& p_{3} \\
& p_{4}
\end{aligned}\left[\begin{array}{lllllllll}
(0.70,0.75) & (0.60,0.55) & (0.80,0.3) & (0.60,0.40) & (0.70,0.50) & (0.55,0.45) & (0.75,0.70) & (0.45,0.25) \\
(0.45,0.75) & (0.35,0.55) & (0.35,0.35) & (0.15,0.40) & (0.25,0.50) & (0.25,0.45) & (0.30,0.70) & (0.25,0.25) \\
(0.25,0.75) & (0.55,0.55) & (0.40,0.35) & (0.25,0.40) & (0.30,0.50) & (0.15,0.45) & (0.35,0.70) & (0.40,0.25)
\end{array}\right]
$$

Step-3: The decision generalized fuzzy soft matrix is

$$
\begin{aligned}
& W M[A, B]=\begin{array}{c}
p_{1} \\
p_{2} \\
p_{3} \\
p_{4}
\end{array}\left[\begin{array}{l}
\frac{(0.70 \times 0.75)+(0.60 \times 0.55)+(0.80 \times 0.35)+(0.60 \times 0.40)+(0.70 \times 0.50)+(0.55 \times 0.45)+(0.75 \times 0.70)+(0.45 \times 0.25)}{0.75+0.55+0.35+0.40+0.50+0.45+0.70+0.25} \\
\frac{(0.45 \times 0.75)+(0.35 \times 0.55)+(0.35 \times 0.35)+(0.15 \times 0.40)+(0.25 \times 0.50)+(0.25 \times 0.45)+(0.30 \times 0.70)+(0.25 \times 0.25)}{0.75+0.55+0.35+0.40+0.50+0.45+0.70+0.25} \\
\frac{(0.25 \times 0.75)+(0.55 \times 0.55)+(0.40 \times 0.35)+(0.25 \times 0.40)+(0.30 \times 0.50)+(0.15 \times 0.45)+(0.35 \times 0.70)+(0.40 \times 0.25)}{0.75+0.55+0.35+0.40+0.50+0.45+0.70+0.25}
\end{array}\right] \\
& \left.=\begin{array}{c}
p_{1} \\
p_{2} \\
p_{3} \\
p_{4}
\end{array}\left[\begin{array}{c}
\frac{2.61}{3.95} \\
\frac{1.4375}{3.95} \\
\frac{1.225}{3.95} \\
\frac{1.2925}{3.95}
\end{array}\right]=\begin{array}{ll}
p_{1} \\
p_{3} & 0.661 \\
p_{4} & 0.364 \\
0.310 \\
0.327
\end{array}\right]
\end{aligned}
$$

Step-4: The maximum weight is 0.661 corresponding to the patient $p_{1}$. Hence the patient $p_{1}$ is suffered in dengue.

It is noted that, the decision found by the "Repeated Average Method of Fuzzy Soft Matrix" has matched with the decision found in (Saikia et al. 2014).

\section{Conclusion}

After the innovation of matrix algebra, it has become a very interesting and sophisticated topic regarding its diversified operation techniques. Moreover for finding any result in any field like business, economics, engineering and medical, matrix notation is frequently being used in modern time especially in computer programming. The researchers and users feel more comfortable, stress free and trustable than any other traditional methods. In addition to develop any software matrix algebra is considered as in advanced level. Considering all these facilities of matrix algebra, repeated average method of fuzzy soft matrix has been applied in this paper to make the decision. The outcome found by the proposed method is mathematically and statistically inspected. In this circumstances researchers must get the coincidence of mathematics and statistics in the same time in 
fuzzy logic. So this method certainly plays a vital rule to make any decision with fuzzy data without any complication. For instance, a problem has been solved by using this method and found this method perform correctly to provide the best result with in a very short time.

\section{References}

Babitha, K. V. and J. J. Sunil. 2010. Soft set relations and functions. Computers Mathematics with Applications Elsevier. 60: 1840-1849.

Babitha, K. V. and J. J. Sunil. 2011. Transitive closures and orderings on soft sets. Computers Mathematics with Applications Elsevier 62: 2235-2239.

Borah, M. J., T. J. Neog and D. K. Sut. 2012. Fuzzy soft matrix theory and its decision making. IJMER. 2(2): 121-127.

Cagman, N. and S. Enginoglu. 2010. Soft matrix theory and its decision making. Computers and Mathematics with Applications Elsevier. 59: 3308- 3314.

Cagman, N. and S. Enginoglu. 2012. Fuzzy soft matrix theory and its application in decision making. Iranian Journal of Fuzzy Systems 9: 109-119.

Hasan, M. K., Md. Yasin Ali, Abeda Sultana and N. K. Mitra. 2019. Decision Making with help of the Repeated Average Method of Fuzzy Soft Matrix. International Journal of Advances in Mathematics 1: 83-91.

Ibrahim, A. M. and A. O. Yusuf. 2012. Development of Soft Set Theory. American International Journal of Contemporary Research 2(9): 205-210.

Mondal, J. I. and T. K. Roy.2013. Theory of a Fuzzy Soft Matrix and its Multi Criteria in Decision Making Based on Three Basic t-Norm Operators. International Journal of Innovative Research in Science, Engineering and Technology 2(10): 5715-5723.

Maji, P.K., R. Biswas and A. R. Roy. 2003. Soft set theory. Computers and mathematics with applications 45: 555-562.

Maji, P.K., R. Biswas and A. R. Roy. 2001.Fuzzy Soft Sets. Journal of Fuzzy Mathematics 9(3): 589-602.

Majumdar, P. and S. K. Samanta. 2010. Generalized fuzzy soft sets. Journal of Computer Mathematics and Applications 59: 1425-1432.

Molodtsov, D. 1999. Soft set theory - first results. Computers and Mathematics with Applications 37:19-31.

Neog, T. J., M. Bora and D. K. Sut. 2012. On Fuzzy soft matrix theory. International Journal of Mathematical Achieve 3(2): 491-500.

Saikia, B. K., H. Boruah and P.K. Das. 2014. An Application of Generalized Fuzzy Soft Matrices in Decision Making Problem. IOSR Journal of Mathematics 10(1): 33-41.

Singh, D. and I. A. Onyeozili. 2012. On Some New Properties of Soft Set Operations. International Journal of Computer Applications 59(4): 39-44.

Tanushree, M. B., N. K. Mahapatra and S. K. Mondal. 2012. Different Types of Matrices in Fuzzy Soft Set Theory and Their Application in Decision Making Problems. An International Journal of Engineering Science and Technology 2(3): 389-398. 